\title{
Adenoid Hypertrophy with Deviated Nasal Septum in Young Adults
}

\author{
Shweta Anand ${ }^{1}$, Mahesh Virupakshi Kattimani ${ }^{2}$ \\ 1,2 Department of ENT, NIMS Medical College, Jaipur, Rajasthan, India.
}

\section{INTRODUCTION}

Adenoid hypertrophy is a common cause of nasal obstruction in children but relatively uncommon in adults, however adenoid hypertrophy in young adults is thought to be a persistence of untreated adenoid hypertrophy of childhood. This case series also notes that adenoid hypertrophy can be associated with deviated nasal septum. Coblation assisted endoscopic adenoidectomy usually has good result in adenoid clearance. Hence, routine endoscopic examination of nasopharynx helps in early diagnosis of adenoid hypertrophy and subsequent better management in young adults with complaints of nasal blockage.

Nasopharyngeal vegetations were earlier described by Wilhelm Meyer in 1870 as forming part of Waldeyer's ring of lymphoid tissue and he coined the term 'adenoid' to describe the same. In younger children, it has been thought that the adenoids may have an important role in development of an immunological memory. Physiologically it has been considered that hypertrophy of adenoid tissue occurs during 6 - 10 years and tend to regress and atrophy at 16 years.

Grading of adenoid hypertrophy as described by Clemens et al. is as follows. ${ }^{1}$

- Grade I: adenoid tissue filling 1/3rd. of the vertical height of choana.

- Grade II: adenoid tissue filling up to 2/3rd of the vertical height of choana.

- Grade III: from 2/3rd to nearly all but not completely filling the choana.

- Grade IV: complete choanal obstruction

We present three cases of adenoid hypertrophy with deviated nasal septums in adults who visited ENT outpatient department (OPD) at National Institute of Medical Sciences, Jaipur during COVID era of January 2021 to April 2021.

\section{PRESENTATION OF CASE}

\section{Case 1}

A 20 year female presented with complaints of bilateral nasal obstruction, left nasal obstruction worse than right, mouth breathing and snoring since childhood. There was no history of fever, nasal discharge and nasal bleeding.

A diagnostic nasal endoscopic examination revealed left sided septal spur and septal deviation with right sided inferior turbinate hypertrophy and a grade 3 adenoid hypertrophy.

Other findings on clinical examination were high arched palate, grade 1 tonsillar hypertrophy and retracted tympanic membrane. Reverse transcriptase polymerase chain reaction (RT PCR) of COVID-19 and other routine investigations were done and patient underwent coblation adenoidectomy with endoscopic septoplasty under general anaesthesia.

\section{Corresponding Author:}

Dr. Mahesh Virupakshi Kattimani, \# 252, F-1, Metroprime -3, Apartments, Manyawas, Jaipur, Rajasthan, India. E-mail:magz0705@gmail.com

DOI: $10.14260 /$ jemds/2021/650

How to Cite This Article:

Anand S, Kattimani MV. Adenoid hypertrophy with deviated nasal septum in young adults. $J$ Evolution Med Dent Sci 2021;10(36):3199-3201,

$10.14260 /$ jemds/2021/650

Submission 04-06-2021,

Peer Review 19-08-2021,

Acceptance 26-08-2021,

Published 06-09-2021.

Copyright (C) 2021 Shweta Anand et al. This is an open access article distributed under Creative Commons Attribution License [Attribution 4.0 International (CC BY 4.0)] 


\section{Case 2}

A 17 year old male presented with bilateral nasal obstruction, worse on the right side and mouth breathing since childhood. There was history of bilateral aural fullness for 2 years on and off. There was no history of nasal discharge or ear discharge.

On endoscopic examination, right sided nasal septal deviation was noted with grade 3 adenoid hypertrophy. Ear examination revealed bilateral retracted tympanic membrane. RT PCR of COVID 19 was negative and other routine preoperative investigations were within normal limits. Patient underwent coblation adenoidectomy and endoscopic septoplasty.

\section{Case 3}

An 18 year old male presented with history of bilateral nasal obstruction however nasal obstruction was more on left side than the right side. A nasal endoscopic examination revealed. Grade 4 adenoid hypertrophy and a sharp left sided septal spur. Oral cavity examination revealed high arched palate.

The patient tested negative for COVID 19 and was fit for surgery as per pre-operative investigations. Coblation adenoidectomy with endoscopic septoplasty completely relieved the nasal obstruction symptom

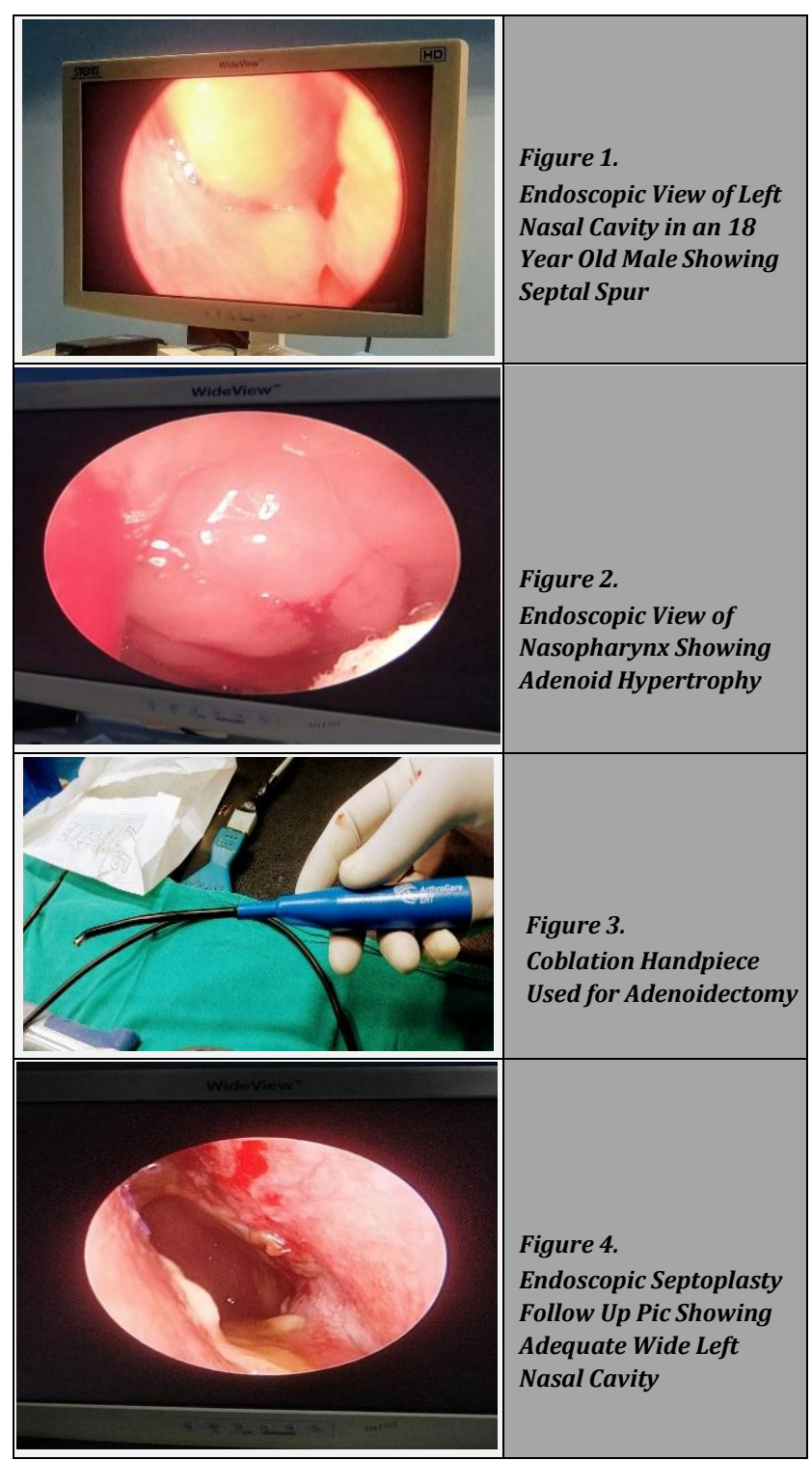

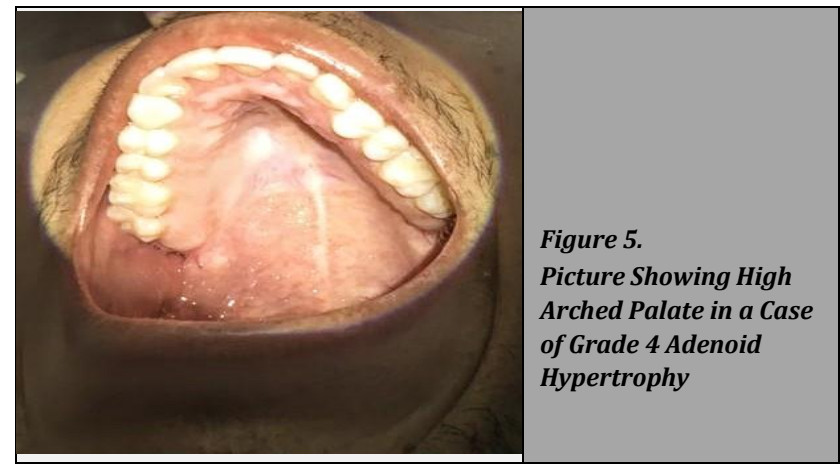

\section{DISCUSSION}

'Long face syndrome' characterized by long lean open mouth, dumb face, crowding of teeth and a typical high arched palate was described by C V Tomes and he coined the term 'Adenoid facies'. ${ }^{2}$ Often nasal obstruction in children can be attributed to adenoid hypertrophy however it can also be found causing nasal obstruction in young adults and adolescents. In our study, we observed three young adults who had simultaneous adenoid hypertrophy and nasal septal deviation. A coexistence of obstructive adenoid hypertrophy and obstructive nasal septal deviation in $25 \%$ of the adult group was found in a study performed at Ankara Military Hospital, Ankara, Turkey by Yildrim et al. $^{3}$

Khan et al. in their study noted that $26.77 \%$ of adenoid hypertrophy patients had deviated nasal septum. ${ }^{4}$ Shetty et al. in their study of 25 cases of adult adenoid hypertrophy noted that adenoidectomy was associated with septoplasty in 5 cases. They observed that adenoid hypertrophy in adults was more common in second and third decade and they concluded that adenoid hypertrophy in adults was persistence of childhood hypertrophy. ${ }^{5}$

While evaluating a young or adolescent patient with deviated nasal septum, adenoid hypertrophy can be ruled out by endoscopic examination of nasopharynx. Nasal endoscopy was used to identify adenoid hypertrophy in 35 adults aged between 20 and 42 years in a study conducted by Kamel et al. They noted that nasopharyngeal examination by a posterior rhinoscopy method was inadequate which in turn may lead to misdiagnosis and resultant maltreatment. In their study, adenoidectomy resulted in marked improvement in 94 per cent of cases without major complications. ${ }^{6}$

A high arched palate often may compress in a caudocranial direction leading to a displaced nasal septum. The deepening of the palatal arch caused due to a transverse maxillary deficiency is often related to continuous oral breathing. Thus, the mouth breathing in the background of nasal obstruction often ends up becoming a closed cycle and gradually worsens with anatomic derangement (Akbay et al. 2013). ${ }^{7}$ A high arched palate exerts pressure gradually during active phase of craniofacial skeletal development. A traumatic insult thus may not be a lone cause for posterior septal deviation. ${ }^{8}$

Linder-Aronson described the sequel of hypertrophic adenoids for the face and coupled its development by changes in muscular balance. The mouth breathing results in a lower tongue position and there is an imbalance between the forces 
from cheeks and tongue which causes a low mandibular position and extended head posture. ${ }^{9}$

In our study, one patient with grade 4 adenoid hypertrophy had a high arched palate which made septal surgery difficult. Care was taken while performing osteotomies to avoid injury to the palatal roof. History ruling out a submucosal cleft is crucial.

Ersoy et al. reported a case of a palatal fistula closure where the history revealed that a previous septoplasty without prior evaluation of submucous cleft had probably led to palatal fistula. ${ }^{10}$

In a rhinology practice, septoplasty was observed to be one of the most frequently performed surgical procedure. If meticulously done with a sound anatomical knowledge, fewer or minimal complications were expected. It was observed by Tilaveridis et al, that palatal perforation was one of the rarest complications. ${ }^{11}$

A reduced blood loss, lower pain grade on post-operative day 1 and no post-operative residual tissue were the significant advantages of coblation adenoidectomy over conventional adenoidectomy noted by Bidaye et al. in their study ${ }^{12}$ Coblation adenoidectomy gave us the advantage of complete clearance of adenoid tissue avoiding chances of recurrence and better recovery in post-operative period. Simultaneous correction of adenoid hypertrophy with deviated nasal septum gave good result in reliving nasal obstruction.

\section{CONCLUSIONS}

From our case series of three case of adenoid hypertrophy with deviated nasal septum in age group of 17 to 21 we conclude that young adult patients with chronic nasal obstruction must be examined by nasal endoscopy keeping in mind that they may have persistent adenoid hypertrophy in coexistence of deviated nasal septum. Further, in such patients, nasal obstruction can be best treated/relieved by adenoidectomy and septoplasty under endoscopic vision. Coblation adenoidectomy has the advantage of complete removal of adenoid tissue and thus minimizing chances of recurrence by simultaneously providing rapid recovery postoperatively. Special care must be taken during septoplasty in such cases with respect to high arched palate.

Financial or other competing interests: None.

Disclosure forms provided by the authors are available with the full text of this article at jemds.com.

\section{REFERENCES}

[1] Clemens J, McMurray JS, Willging JP. Electrocautery versus curette adenoidectomy: comparison of postoperative results. Int $\mathrm{J}$ Pediatr Otorhinolaryngol 1998;43(2):115-22.

[2] Michael H, Brian B, Heinz S, et al. Diagnostic handbook of Otorhinolaryngology. $1^{\text {st }}$ edn. CRC Press 1997.

[3] Yildirim N, Şahan M, Karslioğlu Y. Adenoid hypertrophy in adults: clinical and morphological characteristics. J Int Med Res 2008;36(1):157-62.

[4] Khan MA, Nawaz FUH, Hakim A, et al. Frequency of adenoid hypertrophy among adult patients with nasal obstruction. J Postgrad Med Inst 2018;32(3):262-5.

[5] Shetty S, Aroor R, Bhandary SK, et al. Adult adenoid hypertrophy, is it persistent childhood adenoid hypertrophy? Med J DY Patil Univ 2016;9(2):216-8.

[6] Kamel RH, Ishak EA. Enlarged adenoid and adenoidectomy in adults: endoscopic approach and histopathological study. J Laryngol Otol 1990;104(12):965-7.

[7] Akbay E, Cokkeser Y, Yilmaz 0, et al. The relationship between posterior septum deviation and depth of maxillopalatal arch. Auris Nasus Larynx 2013;40(3):28690.

[8] Torre C, Capasso R, Zaghi S, et al. High incidence of posterior nasal cavity obstruction in obstructive sleep apnea patients. Sleep Science Practice 2017;1:8.

[9] Linder-Aronson S. Adenoids. Their effect on the mode of breathing and nasal airflow and their relationship to characteristics of the facial skeleton and the dentition. A biometric, rhino-manometric and cephalometroradiographic study on children with and without adenoids. Acta Otolaryng Suppl 1970;265:1-132.

[10] Ersoy B, Yilmaz S, Sirinoglu H, et al. A rare complication after septoplasty procedure in a misdiagnosed submucous cleft palate case: palatal fistula. J Plast Reconstr Aesthet Surg 2010;63(8):1382-4.

[11] Tilaveridis I, Kalaitisidou I, Kyrgidis A, et al. Palatal perforation as a rare complication of nasal septoplasty. Aesthetic Plast Surg 2016;40(6):850-3.

[12] Bidaye R, Vaid N, Desarda K. Comparative analysis of conventional cold curettage versus endoscopic assisted coblation adenoidectomy. J Laryngol Otol 2019;133(4):294-9. 